\title{
Clinical features and treatment of maturity onset diabetes of the young (MODY)
}

This article was published in the following Dove Press journal:

Diabetes, Metabolic Syndrome and Obesity:Targets and Therapy 27 April 2012

Number of times this article has been viewed

\author{
Daphne SL Gardner' \\ E Shyong Tai ${ }^{2}$ \\ 'Department of Endocrinology, \\ Singapore General Hospital, \\ ${ }^{2}$ Department of Endocrinology, \\ National University Hospital, \\ Singapore
}

Correspondence: Daphne SL Gardner Department of Endocrinology, Singapore General Hospital, Block 6, Level 6, Outram Road, Singapore 169608 Tel +65 632I 4523

Email daphne.gardner@sgh.com.sg

\begin{abstract}
Maturity onset diabetes of the young (MODY) is a heterogeneous group of disorders that result in $\beta$-cell dysfunction. It is rare, accounting for just $1 \%-2 \%$ of all diabetes. It is often misdiagnosed as type 1 or type 2 diabetes, as it is often difficult to distinguish MODY from these two forms. However, diagnosis allows appropriate individualized care, depending on the genetic etiology, and allows prognostication in family members. In this review, we discuss features of the common causes of MODY, as well as the treatment and diagnosis of MODY.
\end{abstract}

Keywords: type 1 diabetes, type 2 diabetes, HNF1A, HNF4A, HNF1B, GCK

\section{Introduction}

Maturity onset diabetes of the young (MODY) was a term first used in the $1970 \mathrm{~s}^{1,2}$ to describe inheritable diabetes distinct from type 1 (insulin-dependent) and type 2 (noninsulin-dependent) diabetes. In these initial reports, MODY patients displayed a familial form of noninsulin-dependent diabetes, which showed autosomal dominant inheritance and which typically presented before the age of 25 years. The molecular genetic basis of MODY was subsequently recognized in the $1990 \mathrm{~s},{ }^{3-7}$ indicating that genetic mutations result in diabetes primarily through their effects on $\beta$-cell dysfunction. The clinical features of patients with MODY are now known to be heterogeneous, depending on the genetic etiology.

To date, there are mutations in at least nine different genes (Table 1) that result in the MODY phenotype, which accounts for approximately $1 \%-2 \%$ of patients diagnosed with diabetes. ${ }^{8}$ This prevalence is likely underestimated, since large population screening studies have not been performed. Depending on the genetic etiology, the different genetic subtypes differ in terms of age of onset, pattern of hyperglycemia, response to treatment, and extra-pancreatic manifestations. Thus, it would be more appropriate to use the correct monogenic names for young-onset diabetes, since MODY is not a single entity.

Mutations in the genes encoding the nuclear transcription factor 1 homeobox $\mathrm{A}$ $(H N F 1 A)$, the hepatocyte nuclear factor 4 homeobox $(H N F 4 A)$, and the enzyme glucokinase $(G C K)$ are the most common causes of MODY, representing $52 \%, 10 \%$, and $32 \%$ of MODY cases in the UK, respectively. ${ }^{9}$ The reported prevalence of these causes varies across countries due to differences in the frequency of screening for diabetes. For example, in countries where glucose is more frequently performed to screen for diabetes in asymptomatic individuals, $G C K$ mutations (manifesting with mild hyperglycemia) are detected more often. As a consequence, $G C K$ mutations predominate in countries 
Table I Classification of single gene mutations resulting in monogenic diabetes

\begin{tabular}{|c|c|c|}
\hline Gene & $\begin{array}{l}\text { Prevalence amongst } \\
\text { those with MODY }\end{array}$ & Other clinical features \\
\hline HNFIA & $30 \%-50 \% *$ & $\begin{array}{l}\text { Common mutation. Highly penetrant. Large }(>5 \mathrm{mmol} / \mathrm{L}) \text { rise in 2-hour glucose levels on } 75 \mathrm{~g}-\mathrm{OGTT} \text {. } \\
\text { Progressive } \beta \text {-cell failure. Sensitivity to sulphonylureas. }\end{array}$ \\
\hline GCK & $30 \%-50 \% *$ & $\begin{array}{l}\text { Common mutation. Raised fasting glucose levels, with small ( }<3 \mathrm{mmol} / \mathrm{L}) \text { rise in } 2 \text { hour glucose } \\
\text { following } 75 \text { g-OGTT. Mild hyperglycemia; generally does not require treatment. }\end{array}$ \\
\hline HNF4A & $5 \%$ & $\begin{array}{l}\text { Presents in similar manner to HNFIA mutations. Associated with higher birth weight and transient } \\
\text { neonatal hypoglycemia. Progressive } \beta \text {-cell failure. Sensitivity to sulphonylureas. }\end{array}$ \\
\hline HNFIB & $5 \%$ & Characterized by renal disease. Urogenital tract abnormalities in females. \\
\hline INS & $<1 \%$ & $\begin{array}{l}\text { Wide clinical spectrum. Most present with neonatal diabetes, but may also present in early childhood } \\
\text { and adulthood. }\end{array}$ \\
\hline IPFI & $<1 \%$ & $\begin{array}{l}\text { Average age of onset is } 35 \text { years. }{ }^{7} \text { IPFI regulates early pancreatic development. Pancreatic agenesis } \\
\text { seen in homozygotes and compound heterozygotes. }{ }^{83,84}\end{array}$ \\
\hline NEURODI & $\begin{array}{l}<1 \% \text { (fewer than } \\
\text { five families reported) }\end{array}$ & $\begin{array}{l}\text { Very rare, adult onset (mid-20s). Reduced insulin production (developmental } \beta \text {-cell dysfunction). } \\
\text { Individuals may be overweight or obese, similar to type } 2 \text { diabetes. }\end{array}$ \\
\hline CEL & $\begin{array}{l}<\mathrm{I} \% \text { (fewer than } \\
\text { five families reported) }\end{array}$ & $\begin{array}{l}\text { Very rare, adult onset (mean age } 36 \text { years). Exocrine pancreatic insufficiency (dysfunction of the } \\
\text { mature acinar cell). Pathophysiology of endocrine dysfunction not clear. }\end{array}$ \\
\hline PAX4 & $\begin{array}{l}<\mathrm{I} \% \text { (fewer than } \\
\text { five families reported) }\end{array}$ & Only two families described. \\
\hline
\end{tabular}

Note: *Dependent on the populations studied.

Abbreviations: HNFIA, hepatocyte nuclear factor I homeobox A; GCK, glucokinase; HNF4A, hepatocyte nuclear factor 4 homeobox A; HNFIB, hepatocyte nuclear factor I homeobox B; IPFI, insulin promoter factor I; NEURODI, neurogenic differentiation I; CEL, carboxyl ester lipase; PAX4, paired box 4.

such as Germany, Italy, France, and Spain. ${ }^{10,11}$ MODY has also been described in other ethnic groups. ${ }^{6,12}$ However, prevalence in other ethnicities may be underrepresented, since Asian patients make up only $0.5 \%$ of UK referrals for MODY testing, even though there is a significantly higher prevalence of diabetes in Asian patients. ${ }^{12}$

One of the challenges in diagnosing MODY is distinguishing individuals with MODY from those with type 1 or type 2 diabetes, as the clinical features may be similar and there is often an overlap in phenotypes. This review discusses the features of the most common forms of MODY, concentrating on patients presenting with young onset diabetes (between the ages of 10 and 40 years), as well as treatment options. We also discuss the selection of individuals for further genetic testing. Neonatal forms of diabetes, and other forms of monogenic diseases associated with diabetes, such as Donohue syndrome or lipodystrophy, are beyond the scope of this review.

\section{How do patients with MODY present clinically?}

Patients with MODY often have one or more of these features: a strong family history of diabetes of any type, insulin independence, absence of autoantibodies for pancreatic antigens, ${ }^{13}$ and evidence of endogenous insulin production (detection of measurable C-peptide in the presence of hyperglycemia, low insulin requirement $[<0.5$ units $/ \mathrm{kg} / \mathrm{d}]$, or a lack of ketoacidosis when insulin is omitted outside the honeymoon period [typically 5 years following the diagnosis of diabetes]). These features are atypical for type 1 diabetes, thus increasing the probability of monogenic diabetes. However, in those with apparent type 2 diabetes, the absence of insulin resistance features (a lack of obesity, the absence of acanthosis nigricans, normal triglyceride levels, or elevated or normal high-density lipoprotein cholesterol [HDL-C]) can indicate the presence of monogenic $\beta$-cell forms of diabetes.

There are distinct phenotypes in clinical presentation, and these are dependent on the genetic etiology. The various genes involved, and the associated clinical features, are described and then summarized in Table 1.

\section{Genes involved in MODY HNFIA}

Mutations in the $H N F-1 \alpha$ (or HNF1A) gene are the most common cause of MODY in the UK, ${ }^{14}$ and they are a common cause of MODY in other European countries, such as Germany, ${ }^{15}$ Finland and Sweden, ${ }^{16}$ Italy, ${ }^{17}$ and Spain. ${ }^{18}$ Mutations in HNF1A have also been described in the Canadian, ${ }^{19}$ North American, ${ }^{20}$ Japanese, ${ }^{21}$ and Chinese ${ }^{22}$ populations.

The HNF1A gene consists of ten exons and studies of $H N F 1 A$ knockout animals show a reduction in the key steps of glucose transport and metabolism. ${ }^{23}$ In $\beta$-cell lines, mitochondrial metabolism also appears to be reduced. ${ }^{24,25}$ These HNF1A mutations demonstrate a high penetrance, 
with $63 \%$ of carriers developing diabetes by 25 years of age, $79 \%$ by 35 years of age, and $96 \%$ by 55 years of age. The age at diagnosis is partly determined by the location of the mutation: those with mutations in the terminal exons (8-10) are diagnosed on average 8 years earlier than those with mutations in exons $1-6 .{ }^{26}$

Typically, patients heterozygous for $H N F 1 A$ mutations present in adolescence, or early adult life, with progressive $\beta$-cell failure and increasing hyperglycemia. In fact, $\beta$-cell dysfunction is seen to occur before the onset of diabetes in $H N F 1 A$ mutation carriers. Even when blood glucose is in the normal range, $H N F 1 A$ mutation carriers are seen to have a lower insulinogenic index and a lower early insulin response when compared to non-mutation carriers in the same family. ${ }^{27}$ This is clear when the individuals undergo an oral glucose tolerance test, with the 2-hour glucose level frequently being more than $6 \mathrm{mmol} / \mathrm{L}$ higher than the fasting level, even when the fasting glucose level is less than $6 \mathrm{mmol} / \mathrm{L} .^{28}$ Another feature of this group of patients is a low renal threshold for glucose. Glycosuria has been observed in young nondiabetic $H N F 1 A$ mutation carriers. ${ }^{27}$ This is thought to be due to a reduced expression of the sodiumglucose transporter-2, reducing glucose re-absorption through the proximal tubule. ${ }^{29}$

Due to its progressive nature, those with $H N F 1 A$ mutations are at considerable risk of microvascular and macrovascular complications, ${ }^{30,31}$ similar to those with type 1 and type 2 diabetes. The frequency of hypertension appears to be similar to type 1 diabetes. ${ }^{30}$ Raised, rather than low, HDL-C levels are observed in HNF1A MODY patients, which is potentially a useful feature for distinguishing between MODY and type 2 diabetes. ${ }^{32}$

\section{Treatment}

Another important distinguishing feature of $H N F 1 A$ mutations is that afflicted individuals are extremely sensitive to the hypoglycemic effects of sulphonylureas. ${ }^{33-35}$ A randomized cross-over trial, which assessed glycemic responses to the sulphonylurea gliclazide and the metformin, compared patients with $H N F 1 A$ mutations and type 2 diabetes, who were matched for fasting glucose and body mass index. ${ }^{36}$ While the effects of metformin and gliclazide were similar in those with type 2 diabetes, there was a fivefold greater response to gliclazide than metformin in those with $H N F 1 A$ mutations. In addition, the response to gliclazide was fourfold greater in these individuals than in type 2 diabetes patients, while the response to metformin remained similar in both groups.
This finding has large implications, particularly for those previously misdiagnosed with type 1 diabetes, as they may be able to discontinue insulin therapy and be treated with sulphonylureas without risk of ketoacidosis, ${ }^{37}$ even after insulin treatment for a mean of 20 years. A further report, where 34 patients were taken off insulin and given sulphonylurea after a diagnosis of $H N F 1 A$ MODY, showed that 24 of 34 patients were able to remain off insulin for over 3 years, with no deterioration in glycemic control. ${ }^{38}$ Nateglinide has been used in 15 patients with HNF1A MODY, suggesting that prandial secretagogues may be a useful alternative. ${ }^{39}$ Although control may be maintained for many years, most patients eventually progress to insulin treatment.

\section{GCK}

GCK mutations are another common cause of MODY, and those with heterozygous mutations demonstrate mild, stable fasting hyperglycemia $(5.5-8.0 \mathrm{mmol} / \mathrm{L})$ that shows little deterioration with age. Patients are generally asymptomatic, and hyperglycemia is commonly discovered during routine screening, for example during pregnancy or through insurance medicals.

$G C K$ catalyzes the rate-limiting step of glucose phosphorylation, thus enabling the $\beta$-cell and the hepatocyte to respond appropriately to the degree of glycemia. ${ }^{40}$ Heterozygous inactivating mutations reset the glucose threshold for the insulin secretion being regulated to a higher level, producing a higher fasting glucose level. ${ }^{41}$ The insulin production is adequate; therefore, the glucose levels in these individuals rapidly return to normal when they are given an oral glucose load. Most patients with mutations in the $G C K$ have a small increase in plasma glucose $(<3 \mathrm{mmol} / \mathrm{L}$ in $70 \%$ of patients) 2 hours after an oral glucose load. ${ }^{28}$

The majority of patients with MODY due to GCK mutations maintain glycated hemoglobin $\left(\mathrm{HbA}_{1 \mathrm{c}}\right.$ level) below $8 \%,{ }^{42}$ and observational studies suggest that these patients do not develop diabetes-related microvascular complications, despite exposure to hyperglycemia over an average period of 50 years. ${ }^{43,44}$ Although there are little data on longterm macrovascular complications, one larger cohort study seems to suggest there is no increase in the prevalence of dyslipidemia or hypertension in these patients, which raises the possibility that their macrovascular risk may not be significantly elevated. ${ }^{43}$

\section{Treatment}

Given the mild hyperglycemia, the absence of long-term microvascular complications, and the observation that 
treatment has little effect on glycemia in this group of patients, ${ }^{45}$ the general consensus is that the majority of these patients do not require treatment. ${ }^{46}$ The only exception is during pregnancy, in which insulin may be required to prevent excess fetal growth. ${ }^{47}$ This is also dependent on whether the fetus has inherited the GCK mutation ( $50 \%$ chance). If it does not inherit the same $G C K$ mutation as the mother, it will respond to maternal hyperglycemia by producing more insulin, resulting in excess growth. Conversely, if it does inherit the $G C K$ mutation, it will produce normal amounts of insulin, despite the higher level of glycemia, and thus growth will be normal. The glucose-sensing threshold for insulin production is upregulated, such that if a person with the $G C K$ mutation is given exogenous insulin, endogenous insulin secretion is lowered so that the glucose is maintained at their homeostatic set point. Thus treatment with insulin in this situation requires higher than replacement doses to lower the fasting glucose. ${ }^{47}$

\section{HNF4A}

While $H N F 1 A$ and $G C K$ mutations are the most common mutations encountered in monogenic diabetes, $H N F 4 A$ mutations are much less common, reportedly representing $2 \%-5 \%$ of all MODY cases. ${ }^{48-50}$ They present in a similar manner to $H N F 1 A$ carriers, with progressive $\beta$-cell dysfunction, and many patients develop diabetes by the age of 25 .

The detection of $H N F 4 A$ mutation carriers amongst those presenting with type 2 diabetes may be difficult. Useful clinical features include the presence of a family history of diabetes, in particular when onset is before the age of 40, and the absence of insulin resistance markers or obesity in an individual with young-onset type 2 diabetes. ${ }^{51}$ Using these criteria, and excluding those with features suggestive of GCK deficiency, HNF4A mutations have been found to be as high as $10 \%-29 \%$ amongst those negative for $H N F 1 A$ mutations. ${ }^{51,52} H N F 4 A$ mutations should be considered when $H N F 1 A$ analysis does not detect a mutation, but the clinical features are strongly suggestive of $H N F 1 A$ mutations. ${ }^{53}$

HNF4A mutation carriers may also have a lower serum HDL-C, possibly due to reduced ApoA2 transcription, ${ }^{51}$ resulting in lipid profiles not dissimilar to those with type 2 diabetes. In addition, HNF4Amutation carriers tend to have a higher birth weight (mean 800 g greater), with 56\% having macrosomia. Transient neonatal hypoglycemia (15\% of mutation carriers) may precede the onset of diabetes at a later age ${ }^{54}$ This is thought to reflect $H N F 4 A$-induced hyperinsulinism during fetal and neonatal life, with a switch to defective insulin secretion later in life. The mechanism for this remains unclear.

\section{Treatment}

As $\beta$-cell dysfunction is progressive, treatment is required, and low-dose sulphonylureas $(12.5 \%$ or less of the maximum licensed dose) appear to be effective for $H N F 4 A$ diabetes, ${ }^{51}$ which is similar to the response seen with $H N F 1 A$ diabetes. In fact, treatment efficacy with sulphonylureas appears to be sustained even after three decades. ${ }^{55}$ Similar to those with HNF1A mutations, the homeostatic model assessment analysis suggested a marked $\beta$-cell defect in these subjects, but no reduction in insulin sensitivity.

\section{Extra-pancreatic features and other etiologies}

There are several rarer mutations resulting in diabetes-related extra-pancreatic features. Among this group of disorders, one of the more common mutations is in hepatocyte nuclear factor 1 homeobox $\mathrm{B}(H N F 1 B)$.

\section{HNFIB}

HNF1B is encoded by the TCF2 gene and plays a role in the tissue-specific regulation of gene expression in various organs, such as the liver, kidney, intestines, and pancreatic islets, thus influencing their embryonic development. ${ }^{56}$

Patients can develop renal disease, characterized by renal cysts, renal dysplasia, renal-tract malformations, or hypoplastic glomerulocystic kidney disease. ${ }^{57}$ Renal involvement appears to be heterogeneous with a tubulointerstitial profile at presentation, and slowly progressive renal decline throughout adulthood in the absence of diabetic nephropathy. In addition, pancreatic atrophy, genital tract abnormalities in females, and abnormal liver levels have been observed in afflicted individuals. ${ }^{58-60}$ Birth weight is reduced by $800 \mathrm{~g}$ due to reduced insulin secretion in utero. ${ }^{61}$ About half of the $H N F 1 B$ mutation carriers present with early-onset diabetes, which is similar to those with $H N F 1 A$ mutations. ${ }^{62}$ Importantly, spontaneous de novo mutations occur relatively frequently; thus, testing for $H N F 1 B$ mutation should not be discouraged by the absence of a family history of renal disease or diabetes. ${ }^{57}$

\section{Other causes of diabetes with extra-pancreatic features}

These are extremely rare and include the Wolfram syndrome, also known as the DIDMOAD (diabetes insipidus, diabetes mellitus, optic atrophy, and deafness) syndrome, 
the thiamine-responsive megaloblastic anemia syndrome, and maternally inherited diabetes with deafness. ${ }^{63}$ The latter disorder is due to mutations within the mitochondrial genome, resulting in manifestations in metabolically active organs. In particular, in the case of diabetes, mitochondrial dysfunction in the pancreatic islets leads to abnormal $\beta$-cell function, reduction in $\beta$-cell mass, and insulin deficiency. ${ }^{64,65}$ Afflicted individuals can manifest with mitochondrial myopathy, encephalopathy, lactic acidosis, and stroke-like episodes. Although treatment with dietary modification and oral antiglycemic agents may help initially, insulin will usually be required eventually. ${ }^{66}$ Metformin is usually avoided due to the theoretical risk of exacerbating lactic acidosis.

\section{Other etiologies}

Mutations in other genes (predominantly transcription factors), such as neurogenic differentiation 1 (NEUROD1) $)^{67-69}$ and paired box $4(P A X 4),{ }^{70}$ are exceedingly rare causes of MODY; thus, limited data is available. Mutations in the gene encoding the enzyme carboxyl ester lipase have been shown to result in both diabetes and pancreatic exocrine dysfunction. ${ }^{71,72}$

\section{Why is the diagnosis of MODY important?}

Although the diagnosis of MODY is rare, and constitutes only a small proportion of the people afflicted with diabetes, it has important implications. For the individual, it informs optimal treatment options in some instances (eg, the efficacy of sulphonylureas in $H N F 1 A$ and $H N F 4 A$ mutations) and obviates the need for treatment in others (in the case of mild hyperglycemia in $G C K$ mutations). It also allows the future course of the illness to be predicted. It can guide management for the next generation (as in the case of a pregnant $G C K$ patient). Furthermore, once the mutation in the index case is known, this information can be used to quickly and readily confirm the diagnosis in affected family members.

Interestingly, common variants in several genes involved in MODY are associated with an increased risk for developing type 2 diabetes. In recent meta-analyses conducted on type 2 diabetes in East Asians and South Asians, HNF4A single nucleotide polymorphisms were found to be associated with increased risk for type 2 diabetes. ${ }^{73,74}$ Similarly, an insulin (INS) common variant has also been implicated in increased type 2 diabetes risk. ${ }^{75}$ Elucidating the pathophysiology behind monogenic forms of diabetes can help unravel some of the mysteries underlying the pathogenesis of the more common type 2 diabetes.

\section{How is MODY diagnosed?}

MODY is diagnosed through sequencing of the suspected gene, and detecting a mutation. However, molecular genetic testing is expensive and not widely available. It is also evident from the description of the various MODY phenotypes that the clinical spectrum is extremely varied and has significant overlap with both common types of diabetes, making it a challenge to identify MODY patients. As a consequence, many patients with MODY remain undiagnosed. A targeted selection of individuals for genetic testing is necessary to improve the yield of diagnosis, particularly in situations where there are limited resources.

\section{How can we identify patients for testing using clinical criteria?}

Individuals with a strong family history of diabetes, presenting from the second to the fifth decade, should prompt further assessment. The best clinical practice guidelines produced in 2008 advocate assessment for MODY, particularly when the age of presentation for diabetes is $<25$ years old. ${ }^{53}$ The next step would be to look for features inconsistent with the diagnosis of type 1 diabetes (insulin independence, persistently detectable C-peptide, and negative antibody status) or type 2 diabetes (lack of insulin resistance and its markers). Even using these criteria, the detection of MODY is low. ${ }^{76}$

Specific features may increase the likelihood of certain genetic defects and improve the cost-effectiveness of targeted molecular diagnostic testing. This will hopefully improve detection rates for this currently under-diagnosed condition. For example, a low renal threshold (glycosuria at blood glucose levels $<10 \mathrm{mmol} / \mathrm{L}$ ) or a large increase of $>5 \mathrm{mmol} / \mathrm{L}$ on OGTT may raise the suspicion of a $H N F 1 A$ mutation. Recently, genome-wide association studies have found that common variants mapping near the $H N F 1 A$ gene are associated with small alterations in serum C-reactive protein (CRP) levels in healthy individuals. ${ }^{77}$ The presence of $H N F 1 A$ binding sites on the CRP promoter, ${ }^{78}$ and the loss of CRP expression resulting from a loss of $H N F 1 A$ binding, ${ }^{78}$ further supports the hypothesis that $H N F 1 A$ expression and binding influences CRP expression. Motivated by this finding, high-sensitivity CRP was studied and found to be significantly lower in individuals with $H N F 1 A$ gene mutations. ${ }^{79}$ This has since been replicated in larger cohorts. ${ }^{80,81}$ In combination with clinical criteria, the use of high-sensitivity CRP has been shown to greatly improve sensitivity in the detection of HNF1A MODY (up to 90\%), without much loss of specificity. ${ }^{81}$ As another example, mutations in the $G C K$ gene result in mild fasting hyperglycemia or a small 
increment of $<3 \mathrm{mmol} / \mathrm{L}$ of glucose on the OGTT. ${ }^{53}$ However, it is clear that many MODY individuals remain undiagnosed, ${ }^{9}$ or do not fulfill the criteria for referral. ${ }^{82}$

\section{Conclusion}

MODY is a genetically and clinically heterogeneous group of conditions. Its identification remains a challenge for physicians, and the condition is largely underdiagnosed. Yet diagnosis has important implications for the individual, allowing individualized care to be tailored to the underlying genetic causes, and it provides information about the natural history of the disease in individuals. Knowledge of these rare causes of diabetes, the use of additional clinical clues, and other biomarkers will hopefully improve its detection rates, allowing appropriate care and advice to be given to the afflicted person and their family members.

\section{Disclosure}

The authors report no conflicts of interest in this report.

\section{References}

1. Tattersall RB. Mild familial diabetes with dominant inheritance. Q J Med. 1974;43(170):339-357.

2. Tattersall RB, Fajans SS. A difference between the inheritance of classical juvenile-onset and maturity-onset type diabetes of young people. Diabetes. 1975;24(1):44-53.

3. Yamagata K, Furuta H, Oda N, et al. Mutations in the hepatocyte nuclear factor-4alpha gene in maturity-onset diabetes of the young (MODY1). Nature. 1996;384(6608):458-460.

4. Yamagata K, Oda N, Kaisaki PJ, et al. Mutations in the hepatocyte nuclear factor-1alpha gene in maturity-onset diabetes of the young (MODY3). Nature. 1996;384(6608):455-458.

5. Vionnet N, Stoffel M, Takeda J, et al. Nonsense mutation in the glucokinase gene causes early-onset non-insulin-dependent diabetes mellitus. Nature. 1992;356(6371):721-722.

6. Horikawa Y, Iwasaki N, Hara M, et al. Mutation in hepatocyte nuclear factor-1 beta gene (TCF2) associated with MODY. Nat Genet. 1997;17(4):384-385.

7. Stoffers DA, Ferrer J, Clarke WL, Habener JF. Early-onset type-II diabetes mellitus (MODY4) linked to IPF1. Nat Genet. 1997;17(2):138-139.

8. Shepherd M, Ellis I, Ahmad AM, et al. Predictive genetic testing in maturity-onset diabetes of the young (MODY). Diabet Med. 2001;18(5):417-421.

9. Shields BM, Hicks S, Shepherd MH, Colclough K, Hattersley AT, Ellard S. Maturity-onset diabetes of the young (MODY): how many cases are we missing? Diabetologia. 2010;53(12):2504-2508.

10. Estalella I, Rica I, Perez de Nanclares G, et al. Mutations in GCK and HNF-1alpha explain the majority of cases with clinical diagnosis of MODY in Spain. Clin Endocrinol (Oxf). 2007;67(4):538-546.

11. Schober E, Rami B, Grabert M, et al. Phenotypical aspects of maturityonset diabetes of the young (MODY diabetes) in comparison with type 2 diabetes mellitus (T2DM) in children and adolescents: experience from a large multicentre database. Diabet Med. 2009;26(5):466-473.

12. Porter JR, Rangasami JJ, Ellard S, et al. Asian MODY: are we missing an important diagnosis? Diabet Med. 2006;23(11):1257-1260.

13. McDonald TJ, Colclough K, Brown R, et al. Islet autoantibodies can discriminate maturity-onset diabetes of the young (MODY) from Type 1 diabetes. Diabet Med. 2011;28(9):1028-1033.
14. Frayling TM, Bulamn MP, Ellard S, et al. Mutations in the hepatocyte nuclear factor-1alpha gene are a common cause of maturity-onset diabetes of the young in the UK. Diabetes. 1997;46(4):720-725.

15. Kaisaki PJ, Menzel S, Lindner T, et al. Mutations in the hepatocyte nuclear factor-1alpha gene in MODY and early-onset NIDDM: evidence for a mutational hotspot in exon 4. Diabetes. 1997;46(3):528-535.

16. Lehto M, Wipemo C, Ivarsson SA, et al. High frequency of mutations in MODY and mitochondrial genes in Scandinavian patients with familial early-onset diabetes. Diabetologia. 1999;42(9):1131-1137.

17. Gragnoli C, Cockburn BN, Chiaramonte F, et al. Early-onset type II diabetes mellitus in Italian families due to mutations in the genes encoding hepatic nuclear factor 1 alpha and glucokinase. Diabetologia. 2001;44(10):1326-1329.

18. Costa A, Bescos M, Velho G, et al. Genetic and clinical characterisation of maturity-onset diabetes of the young in Spanish families. Eur J Endocrinol. 2000;142(4):380-386.

19. McKinney JL, Cao H, Robinson JF, et al. Spectrum of HNF1A and GCK mutations in Canadian families with maturity-onset diabetes of the young (MODY). Clin Invest Med. 2004;27(3):135-141.

20. Glucksmann MA, Lehto M, Tayber O, et al. Novel mutations and a mutational hotspot in the MODY3 gene. Diabetes. 1997;46(6): 1081-1086.

21. Iwasaki N, Oda N, Ogata M, et al. Mutations in the hepatocyte nuclear factor-1alpha/MODY3 gene in Japanese subjects with early- and lateonset NIDDM. Diabetes. 1997;46(9):1504-1508.

22. Xu JY, Dan QH, Chan V, et al. Genetic and clinical characteristics of maturity-onset diabetes of the young in Chinese patients. Eur J Hum Genet. 2005;13(4):422-427.

23. Pontoglio M, Sreenan S, Roe M, et al. Defective insulin secretion in hepatocyte nuclear factor 1alpha-deficient mice. $J$ Clin Invest. 1998;101(10):2215-2222.

24. Wang H, Maechler P, Hagenfeldt KA, Wollheim CB. Dominantnegative suppression of HNF-1alpha function results in defective insulin gene transcription and impaired metabolism-secretion coupling in a pancreatic beta-cell line. EMBO J. 1998;17(22):6701-6713.

25. Wollheim CB. Beta-cell mitochondria in the regulation of insulin secretion: a new culprit in type II diabetes. Diabetologia. 2000;43(3): 265-277.

26. Harries LW, Ellard S, Stride A, Morgan NG, Hattersley AT. Isomers of the TCF1 gene encoding hepatocyte nuclear factor-1 alpha show differential expression in the pancreas and define the relationship between mutation position and clinical phenotype in monogenic diabetes. Hum Mol Genet. 2006;15(14):2216-2224.

27. Stride A, Ellard S, Clark P, et al. Beta-cell dysfunction, insulin sensitivity, and glycosuria precede diabetes in hepatocyte nuclear factor1alpha mutation carriers. Diabetes Care. 2005;28(7):1751-1756.

28. Stride A, Vaxillaire M, Tuomi T, et al. The genetic abnormality in the beta cell determines the response to an oral glucose load. Diabetologia. 2002;45(3):427-435.

29. Pontoglio M, Prie D, Cheret C, et al. HNF1alpha controls renal glucose reabsorption in mouse and man. EMBO Rep. 2000;1(4):359-365.

30. Isomaa $\mathrm{B}$, Henricsson $\mathrm{M}$, Lehto $\mathrm{M}$, et al. Chronic diabetic complications in patients with MODY3 diabetes. Diabetologia. 1998;41(4): $467-473$.

31. Steele AM, Shields BM, Shepherd M, Ellard S, Hattersley AT, Pearson ER. Increased all-cause and cardiovascular mortality in monogenic diabetes as a result of mutations in the HNF1A gene. Diabet Med. 2010;27(2):157-161.

32. Pearson ER. HDL-cholesterol: differentiating between HNF1A MODY and type 2 diabetes (abstract). 2003;20(S22):S21-S33.

33. Heiervang E, Folling I, Sovik O, et al. Maturity-onset diabetes of the young. Studies in a Norwegian family. Acta Paediatr Scand. 1989;78(1): 74-80.

34. Sovik O, Njolstad P, Folling I, Sagen J, Cockburn BN, Bell GI. Hyperexcitability to sulphonylurea in MODY3. Diabetologia. 1998; 41(5):607-608. 
35. Pearson ER, Liddell WG, Shepherd M, Corrall RJ, Hattersley AT. Sensitivity to sulphonylureas in patients with hepatocyte nuclear factor-1alpha gene mutations: evidence for pharmacogenetics in diabetes. Diabet Med. 2000;17(7):543-545.

36. Pearson ER, Starkey BJ, Powell RJ, Gribble FM, Clark PM, Hattersley AT. Genetic cause of hyperglycaemia and response to treatment in diabetes. Lancet. 2003;362(9392):1275-1281.

37. Shepherd M, Pearson ER, Houghton J, Salt G, Ellard S, Hattersley AT. No deterioration in glycemic control in HNF-1alpha maturity-onset diabetes of the young following transfer from long-term insulin to sulphonylureas. Diabetes Care. 2003;26(11):3191-3192.

38. Shepherd M, Shields B, Ellard S, Rubio-Cabezas O, Hattersley AT. A genetic diagnosis of HNF1A diabetes alters treatment and improves glycaemic control in the majority of insulin-treated patients. Diabet Med. 2009;26(4):437-441.

39. Tuomi T, Honkanen EH, Isomaa B, Sarelin L, Groop LC. Improved prandial glucose control with lower risk of hypoglycemia with nateglinide than with glibenclamide in patients with maturity-onset diabetes of the young type 3. Diabetes Care. 2006;29(2):189-194.

40. Matschinsky FM. Evolution of the glucokinase glucose sensor paradigm for pancreatic beta cells. Diabetologia. 1993;36(11): 1215-1217.

41. Byrne MM, Sturis J, Clement K, et al. Insulin secretory abnormalities in subjects with hyperglycemia due to glucokinase mutations. J Clin Invest. 1994;93(3):1120-1130.

42. Martin D, Bellanne-Chantelot C, Deschamps I, Froguel P, Robert JJ, Velho G. Long-term follow-up of oral glucose tolerance test-derived glucose tolerance and insulin secretion and insulin sensitivity indexes in subjects with glucokinase mutations (MODY2). Diabetes Care 2008;31(7):1321-1323.

43. Velho G, Blanche H, Vaxillaire M, et al. Identification of 14 new glucokinase mutations and description of the clinical profile of 42 MODY-2 families. Diabetologia. 1997;40(2):217-224.

44. Steele AM, Shields BM, Shepherd M, Ellard S, Colclough K, Hattersley AT. Microvascular complication risk in patients with 50 years of moderate hyperglycaemia: are target ranges for glycaemic control appropriate? Abstract A77. Diabet Med. 2011;28(S1):2.

45. Hattersley AT, Pearson ER. Minireview: pharmacogenetics and beyond: the interaction of therapeutic response, beta-cell physiology, and genetics in diabetes. Endocrinology. 2006;147(6):2657-2663.

46. Hattersley A, Bruining J, Shield J, Njolstad P, Donaghue KC. The diagnosis and management of monogenic diabetes in children and adolescents. Pediatr Diabetes. 2009;10 Suppl 12:33-42.

47. Spyer G, Hattersley AT, Sykes JE, Sturley RH, MacLeod KM. Influence of maternal and fetal glucokinase mutations in gestational diabetes. Am J Obstet Gynecol. 2001;185(1):240-241.

48. Malecki MT, Yang Y, Antonellis A, Curtis S, Warram JH, Krolewski AS. Identification of new mutations in the hepatocyte nuclear factor 4alpha gene among families with early onset Type 2 diabetes mellitus. Diabet Med. 1999;16(3):193-200.

49. Pruhova S, Ek J, Lebl J, et al. Genetic epidemiology of MODY in the Czech republic: new mutations in the MODY genes HNF-4alpha, GCK and HNF-1alpha. Diabetologia. 2003;46(2):291-295.

50. Frayling TM, Evans JC, Bulman MP, et al. beta-cell genes and diabetes: molecular and clinical characterization of mutations in transcription factors. Diabetes. 2001;50 Suppl 1:S94-S100.

51. Pearson ER, Pruhova S, Tack CJ, et al. Molecular genetics and phenotypic characteristics of MODY caused by hepatocyte nuclear factor 4alpha mutations in a large European collection. Diabetologia. 2005;48(5):878-885.

52. Carette C, Dubois-Laforgue D, Saint-Martin C, et al. Familial youngonset forms of diabetes related to HNF4A and rare HNF1A molecular aetiologies. Diabet Med. 2010;27(12):1454-1458.

53. Ellard S, Bellanne-Chantelot C, Hattersley AT. Best practice guidelines for the molecular genetic diagnosis of maturity-onset diabetes of the young. Diabetologia. 2008;51(4):546-553.
54. Pearson ER, Boj SF, Steele AM, et al. Macrosomia and hyperinsulinaemic hypoglycaemia in patients with heterozygous mutations in the HNF4A gene. PLoS Med. 2007;4(4):e118.

55. Fajans SS, Brown MB. Administration of sulfonylureas can increase glucose-induced insulin secretion for decades in patients with maturityonset diabetes of the young. Diabetes Care. 1993;16(9):1254-1261.

56. Coffinier C, Thepot D, Babinet C, Yaniv M, Barra J. Essential role for the homeoprotein vHNF1/HNF1beta in visceral endoderm differentiation. Development. 1999;126(21):4785-4794.

57. Ulinski T, Lescure S, Beaufils S, et al. Renal phenotypes related to hepatocyte nuclear factor-1beta (TCF2) mutations in a pediatric cohort. J Am Soc Nephrol. 2006;17(2):497-503.

58. Iwasaki $\mathrm{N}$, Ogata $\mathrm{M}$, Tomonaga $\mathrm{O}$, et al. Liver and kidney function in Japanese patients with maturity-onset diabetes of the young. Diabetes Care. 1998;21(12):2144-2148.

59. Montoli A, Colussi G, Massa O, et al. Renal cysts and diabetes syndrome linked to mutations of the hepatocyte nuclear factor-1 beta gene: description of a new family with associated liver involvement. Am J Kidney Dis. 2002;40(2):397-402.

60. Bellanne-Chantelot C, Chauveau D, Gautier JF, et al. Clinical spectrum associated with hepatocyte nuclear factor-1beta mutations. Ann Intern Med. 6 2004;140(7):510-517.

61. Edghill EL, Bingham C, Slingerland AS, et al. Hepatocyte nuclear factor-1 beta mutations cause neonatal diabetes and intrauterine growth retardation: support for a critical role of HNF-1beta in human pancreatic development. Diabet Med. 2006;23(12):1301-1306.

62. Faguer S, Decramer S, Chassaing N, et al. Diagnosis, management, and prognosis of HNF1B nephropathy in adulthood. Kidney Int. 2011;80(7):768-776.

63. Goto Y, Nonaka I, Horai S. A mutation in the tRNA(Leu)(UUR) gene associated with the MELAS subgroup of mitochondrial encephalomyopathies. Nature. 13, 1990;348(6302):651-653.

64. Kobayashi T, Nakanishi K, Nakase H, et al. In situ characterization of islets in diabetes with a mitochondrial DNA mutation at nucleotide position 3243. Diabetes. 1997;46(10):1567-1571.

65. Walker M, Taylor RW, Stewart MW, et al. Insulin and proinsulin secretion in subjects with abnormal glucose tolerance and a mitochondria tRNA(Leu(UUR)) mutation. Diabetes Care. 1995;18(11):1507-1509.

66. Maassen JA, 'T Hart LM, Van Essen E, et al. Mitochondrial diabetes: molecular mechanisms and clinical presentation. Diabetes. 2004; 53 Suppl 1:S103-S109.

67. Kristinsson SY, Thorolfsdottir ET, Talseth B, et al. MODY in Iceland is associated with mutations in HNF-1alpha and a novel mutation in NeuroD1. Diabetologia. 2001;44(11):2098-2103.

68. Liu L, Furuta H, Minami A, et al. A novel mutation, Ser159Pro in the NeuroD1/BETA2 gene contributes to the development of diabetes in a Chinese potential MODY family. Mol Cell Biochem. 2007;303(1-2):115-120.

69. Malecki MT, Jhala US, Antonellis A, et al. Mutations in NEUROD1 are associated with the development of type 2 diabetes mellitus. Nat Genet. 1999;23(3):323-328.

70. Plengvidhya N, Kooptiwut S, Songtawee N, et al. PAX4 mutations in Thais with maturity onset diabetes of the young. J Clin Endocrinol Metab. 2007;92(7):2821-2826.

71. Raeder H, Johansson S, Holm PI, et al. Mutations in the CEL VNTR cause a syndrome of diabetes and pancreatic exocrine dysfunction. Nat Genet. 2006;38(1):54-62.

72. Jo W, Endo M, Ishizu K, Nakamura A, Tajima T. A novel PAX4 mutation in a Japanese patient with maturity-onset diabetes of the young Tohoku J Exp Med. 2011;223(2):113-118.

73. Cho YS, Chen $\mathrm{CH}, \mathrm{Hu} \mathrm{C}$, et al. Meta-analysis of genome-wide association studies identifies eight new loci for type 2 diabetes in east Asians. Nat Genet. 2012;44(1):67-72.

74. Kooner JS, Saleheen D, Sim X, et al. Genome-wide association study in individuals of South Asian ancestry identifies six new type 2 diabetes susceptibility loci. Nat Genet. 2011;43(10):984-989. 
75. Saxena R, Elbers CC, Guo Y, et al. Large-scale gene-centric metaanalysis across 39 studies identifies type 2 diabetes loci. Am J Hum Genet. 2012;90(3):410-425.

76. Thanabalasingham G, Pal A, Farmer AJ, Ellard S, McCarthy MI, Owen KR. Extending criteria for genetic testing increases diagnosis of maturity-onset diabetes of the young. Diabetologia. 2010;53:S63.

77. Reiner AP, Barber MJ, Guan Y, et al. Polymorphisms of the HNF1A gene encoding hepatocyte nuclear factor-1 alpha are associated with C-reactive protein. Am J Hum Genet. 2008;82(5):1193-1201.

78. Toniatti C, Demartis A, Monaci P, Nicosia A, Ciliberto G. Synergistic trans-activation of the human $\mathrm{C}$-reactive protein promoter by transcription factor $\mathrm{HNF}-1$ binding at two distinct sites. EMBO J. 1990;9(13):4467-4475.

79. Owen KR, Thanabalasingham G, James TJ, et al. Assessment of highsensitivity C-reactive protein levels as diagnostic discriminator of maturity-onset diabetes of the young due to HNF1A mutations. Diabetes Care. 2010;33(9):1919-1924.
80. McDonald TJ, Shields BM, Lawry J, et al. High-sensitivity CRP discriminates HNF1A-MODY from other subtypes of diabetes. Diabetes Care. 2011;34(8):1860-1862.

81. Thanabalasingham G, Shah N, Vaxillaire M, et al. A large multicentre European study validates high-sensitivity C-reactive protein (hsCRP) as a clinical biomarker for the diagnosis of diabetes subtypes. Diabetologia. 2011;54(11):2801-2810.

82. Bellanne-Chantelot C, Levy DJ, Carette C, et al. Clinical characteristics and diagnostic criteria of maturity-onset diabetes of the young (MODY) due to molecular anomalies of the HNF1A gene. J Clin Endocrinol Metab. 2011;96(8):E1346-E1351.

83. Schwitzgebel VM, Mamin A, Brun T, et al. Agenesis of human pancreas due to decreased half-life of insulin promoter factor 1.J Clin Endocrinol Metab. 2003;88(9):4398-4406.

84. Thomas IH, Saini NK, Adhikari A, et al. Neonatal diabetes mellitus with pancreatic agenesis in an infant with homozygous IPF-1 Pro63fsX60 mutation. Pediatr Diabetes. 2009;10(7):492-496.

\section{Publish your work in this journal}

Diabetes, Metabolic Syndrome and Obesity: Targets and Therapy is an international, peer-reviewed open-access journal committed to the rapid publication of the latest laboratory and clinical findings in the fields of diabetes, metabolic syndrome and obesity research. Original research, review, case reports, hypothesis formation, expert opinion and commentaries are all considered for publication. The manuscript management system is completely online and includes a very quick and fair peer-review system, which is all easy to use. Visit http://www.dovepress.com/testimonials.php to read real quotes from published authors.

Submit your manuscript here: http://www.dovepress.com/diabetes-metabolic-syndrome-and-obesity-targets-and-therapy-journal 